\title{
A distinção entre conhecer e pensar em Hannah Arendt e sua relevância para a educação
}

Vanessa Sievers de Almeida

Universidade de São Paulo

\section{Resumo}

A educação, preocupada principalmente com a aquisição de competências e/ou a transmissão de conhecimentos, tem dado pouca atenção para a compreensão do mundo - isto é, um modo de pensar que não tem como objetivo primeiro a resolução de problemas. Para entender melhor a relevância dessa questão, recorremos à distinção que Hannah Arendt traça entre o pensar e o conhecer. A abordagem da autora sobre essas atividades do espírito foi desencadeada pelo processo de Eichmann em Jerusalém. Na ocasião, ela observa que o réu foi capaz de coordenar a deportação dos judeus para os campos de concentração, mas era incapaz de refletir sobre o significado de seus atos. Depois, em sua obra A vida do espírito, ela veio a constatar que conhecimento e pensamento são duas faculdades distintas. 0 conhecer diz respeito à busca da verdade. Os conhecimentos possuem uma validade geral e uma utilidade. A atividade cognitiva, no entanto, mostra-se limitada por ser incapaz de atribuir um significado à nossa relação com o mundo. A busca de sentido é específica do pensamento, a reflexão sobre as experiências, cujos “resultados”, porém, são "fugidios" e, muitas vezes, julgados inúteis. Este artigo, contudo, sustenta que o pensar, enquanto busca de sentido, é essencial para uma educação que, além de possibilitar um saber e um saber fazer, pretende contribuir para que os jovens estabeleçam uma relação de sentido e de pertença com o mundo humano.

\section{Palavras-chave}

Filosofia da educação - Hannah Arendt - Pensamento Conhecimento. 


\title{
The distinction between knowing and thinking in Hannah Arendt and its relevance to education
}

Vanessa Sievers de Almeida

Universidade de São Paulo

\begin{abstract}
Education, chiefly concerned with the acquisition of competences and/or with the transmission of knowledge, has paid little attention to understanding the world - that is to say, to a mode of thinking that does not have as its primary objective the solution of problems. To better understand the relevance of this issue, we look into the distinction established by Hannah Arendt between thinking and knowing. Her approach to these activities of the human spirit was born out of the Eichmann process in Jerusalem. At that time, she observed that the defendant had been capable of coordinating the deportation of Jews to concentration camps, but was incapable of reflecting upon the meaning of his own actions. Later, in her The life of the mind, she recognized that knowledge and thinking are two distinct faculties. The knowing has to do with the search for the truth. Knowledges have a general validity, and usefulness. The cognitive activity, however, turns out to be limited, because it is incapable of attributing meaning to our relationship with the world. The search for meaning is specific to the thinking, to the reflection on experiences, whose "results" are, nevertheless, "elusive" and often seen as useless. In spite of that, this article argues that thinking, as a search for meaning, is essential to an education that, beyond achieving a knowledge and a know-how, aims at contributing to help youngsters to establish a relationship with the human world of meaning and belonging.
\end{abstract}

\section{Keywords}

Philosophy of education - Hannah Arendt - Thinking Knowledge.

\footnotetext{
Contact:
}

Vanessa Sievers de Almeida

Rua Hermínio Falcon, 144

07082-620 - Guarulhos - SP

E-mail: vanessa.sievers@terra.com.br 
Numa sociedade em que conhecimento e tecnologia ganham cada vez mais importância e o repertório de competências e saberes necessários para a vida cotidiana e para a competição no mercado de trabalho sofre constantes renovações, há uma preocupação crescente por parte da escola em acompanhar o que se denomina de progresso científico e tecnológico. Como os conhecimentos da geração mais velha se mostram em parte obsoletos, muitas vezes chega-se à conclusão de que eles têm pouco a oferecer num mundo em constante mudança. Desse modo, os professores perderam o papel de quem apresenta aos mais jovens um universo de cultura e saberes para se transformarem em auxiliares dos alunos na corrida dos novos conhecimentos e tecnologias. Nesse quadro, a educação visa um futuro desconhecido e, seja qual for a sua contribuição, seu trabalho sempre será insuficiente ante as novas demandas.

Em contraposição a essa visão, a filósofa e pensadora do político Hannah Arendt sustenta que a educação, em princípio, se volta para o passado, porque nela introduzimos os mais novos num mundo que os antecede e que é mais velho do que eles. As crianças precisam conhecer e se apropriar do legado que lhes será entregue.

Segundo a autora, esse mundo e as formas de nele viver e de agir não se resumem às preocupações ligadas ao desenvolvimento de instrumentos, métodos ou técnicas para satisfazer da melhor forma as nossas necessidades e desejos, sejam eles de ordem individual ou coletiva.

É verdade que os homens, assim como todos os seres vivos, precisam cuidar das suas necessidades para sobreviver e, para tanto, trabalham e consomem os produtos do trabalho. Também é necessário que construam um espaço - composto por artefatos como, por exemplo, cadeiras e mesas, casas e ruas - que lhes garanta um lugar seguro e duradouro, no meio do incessante ritmo de produção e consumo e de uma natureza na qual tudo surge e desaparece constantemente.

Para melhor resolver essas demandas, eles lançam mão de saberes, técnicas e instrumentos. As crianças deverão adquirir as compe- tências e os conhecimentos para poder se inserir nesses processos de trabalho e fabricação.

0 mundo humano, porém, também é um espaço constituído pela ação humana e o pensamento sobre ele. As nossas atividades não são regidas apenas pelas exigências da necessidade ou da utilidade, mas também somos capazes de estabelecer relações e de criar formas de convivência que não obedecem a fins utilitários. 0 mundo que as crianças herdam é o espaço do trabalho e da fabricação, mas também o lugar da convivência e das histórias humanas. Para Arendt, a educação tem por tarefa familiarizar os educandos com experiências e compreensões compartilhadas, instituições e práticas, saberes e pensamentos que foram constitutivos para o mundo.

Os jovens futuramente assumirão a responsabilidade por esse espaço comum, que poderão renovar ou conservar, mas primeiramente precisam conhecê-lo e encontrar o seu lugar nele. Esse processo de descobrir e desenhar a sua pertença ao mundo está vinculado à capacidade de refletir sobre aquilo que se passa nele e de se perguntar o que está realmente em questão. Essa reflexão Arendt denomina pensamento.

Conhecer e pensar o mundo são, portanto, fundamentais para a educação. A sociedade moderna, contudo - e a escola acompanha esse movimento -, valoriza cada vez mais o conhecer e relega o pensar, enquanto busca de sentido, a um segundo plano, ou então o menospreza por ser pouco útil e por não obter resultados sólidos.

Com o intuito de resgatar a faculdade do pensamento, Arendt procura entender o que distingue essas duas faculdades. Esse tema faz parte de suas reflexões sobre as faculdades do espírito, enquanto a sua abordagem da educação se insere num outro momento da sua obra. Sustentamos, contudo, que a distinção apontada é de especial relevância para a nossa discussão sobre educação. Assim, este trabalho se concentra nessa distinção e remete apenas marginalmente ao conceito de educação da autora.

Como referência principal, temos sua última obra, intitulada $A$ vida do espirito. Nela 
Arendt pretendia escrever sobre três faculdades do espírito: o pensar, o querer e o julgar, mas chega a concluir somente as duas primeiras partes. Nosso interesse se volta para $O$ pensar, e, para tratar dessa questão de modo mais específico, estudamos um capítulo em que a autora aborda a distinção entre pensar e conhecer. A partir daí tecemos algumas reflexões sobre a relevância dessa distinção e de cada uma dessas atividades para a educação.

\section{Ponto de partida}

Hannah Arendt é conhecida, sobretudo, por seu pensamento sobre política, ação e espaço público. Somente numa segunda fase de sua obra ela aborda as atividades do espírito e suas implicações éticas.

Para compreender melhor a preocupação que movimenta sua obra tardia, abordaremos, em primeiro lugar, os acontecimentos que fizeram a autora se dedicar à vida do espírito e apontamos para as questões que a inquietam ao tratar desse tema.

Sua preocupação com as faculdades do pensar, querer e julgar foi provocada, como ela mesma afirma, pelo julgamento de Eichmann em 1961 em Jerusalém, ao qual ela assiste como enviada da revista New Yorker. 0 nazista Adolf Eichmann foi um dos principais responsáveis pela organização da "solução final" ("Endlösung"), termo que se referia à exterminação dos judeus. Arendt escreve um relatório sobre o processo, depois publicado como livro sob o título Eichmann em Jerusalém.

Ao acompanhar o julgamento, Arendt se indaga como esse homem pôde ser capaz de cometer tais monstruosidades. Ela se surpreende por ter diante de si alguém absolutamente comum, uma pessoa normal, que não se mostrava demoníaca. Não havia maldade na pessoa de Eichmann. Ele pouco tinha a ver com os "vilões" como geralmente os imaginamos, nem agiu, como esses, por fraqueza ou por inveja, cobiça ou soberba, apenas tinha cumprido sua função. Não teve nenhum motivo para come- ter os crimes indescritiveis dos quais tratava o processo, isto é, não houve sequer uma razão que pudesse esclarecê-los minimamente. 0 que, entretanto, chamava a atenção no réu era sua superficialidade, sua incapacidade de refletir sobre o acontecido e de pensar sobre o significado de seus atos. Isso leva Arendt (1995) a se indagar:

Será possível que o problema do bem e do mal [...] esteja conectado com a nossa faculdade de pensar? [...] seria possível que a atividade do pensamento como tal [...] estivesse dentre as condições que levam os homens a se absterem de fazer o mal, ou mesmo que ela realmente os "condicione" contra ele? (p. 6-7)

Dessa forma, o olhar da autora se volta para as atividades do espírito.

A ausência de pensamento, na análise de Arendt, não diz respeito a alguma limitação cognitiva, não tem a ver com estupidez (Dummheit) ou ignorância. Isso é válido também para outros nazistas, que, para cometer atrocidades, foram capazes de aplicar conhecimentos e tecnologias avançados, ou mesmo de produzir conhecimentos novos, mas foram incapazes de refletir sobre aquilo que estavam fazendo. Assim, mesmo que tenham feito uso de um saber e de um saber fazer, não pensaram, já que não pararam para se perguntar sobre o sentido de seus atos e não se indagaram o que tudo aquilo significava para eles, nem para as vítimas, nem para o mundo, lugar da convivência no plural (Arendt, 2004). Nesse sentido, a autora constata que pode haver pessoas muito inteligentes que, contudo, não pensam. Conhecimentos e habilidades, ciência e tecnologia, podem, portanto, ser despojados da reflexão que procura compreender o sentido de atos e acontecimentos.

Se a ausência de pensamento pode ter consequências catastróficas, como mostra o caso de Eichmann, o próprio pensar também não está isento de perigos. Isso mostra outra experiência marcante para Arendt, que diz respeito aos intelectuais alemães - entre eles Heidegger 
-, durante o regime nacional-socialista, que aderiram ao nazismo ou não se posicionaram contra o regime de Hitler. Muitos, fechando os olhos diante dos acontecimentos reais, ainda produziram teorias inteligentes sobre a ideologia nacional-socialista. Arendt (1976) expressa a sua indignação com isso numa entrevista dada à TV alemã nos anos 60:

[...] a respeito de Hitler eles tiveram ideias: e, em parte, coisas extremamente interessantes! Muito fantásticas e interessantes e complicadas! E coisas que pairam bem acima do nível comum! Para mim, isso era grotesco! (p. 21, tradução nossa)

Ela relata que havia resolvido não fazer parte disso - "Não quero ter nada a ver com essa companhia”. Em consequência, se afasta da filosofia e escolhe a teoria política como campo de sua atuação acadêmica. 0 caso de Eichmann a faz rever essa decisão, embora ela continue insistindo em não ser chamada de "filósofa". Mesmo no prefácio de sua obra mais filosófica, A vida do espírito (1995), ela explica: "não pretendo nem ambiciono ser um "filósofo”" (p. 5).

0 caso dos intelectuais instiga a sua reflexão teórica sobre a faculdade do pensamento, para a qual, apesar de tudo, recorre a seus conhecimentos filosóficos extraordinários. Arendt acaba por sustentar que há um perigo inerente à própria atividade do pensamento. Esta pressupõe o afastamento das atividades concretas, já que, enquanto estamos envolvidos com problemas e atividades, planejando e procurando soluções, não temos a distância suficiente para indagar sobre o sentido das coisas. Essa retirada do mundo, embora necessária para a atividade do espírito, expõe o eu pensante ao risco de se isolar das experiências reais e girar apenas em torno de si mesmo. 0 filósofo, que em seu pensamento solitário se ocupa com esferas supostamente superiores às contingências da vida cotidiana e aos acontecimentos políticos, corre o perigo de se esquecer da sua responsabilidade pelo mundo. A esse tipo de filosofia
Arendt contrapõe um pensamento "engajado". Nele, mesmo que a reflexão não tenha nenhuma função prática e embora o eu pensante se distancie provisoriamente do andamento das coisas, estamos preocupados com aquilo que se passa no mundo.

Em sua obra A vida do espirito, Arendt procura compreender e descrever essa faculdade do espírito. Nas entrelinhas, porém, sentimos certa relutância, talvez em razão da história dos diversos desvios dos pensadores com os quais não deseja ser identificada. Consequentemente, a autora se vê diante da necessidade de delimitar seu conceito de pensamento e explicitar sempre o que não quer dizer. Há duas questões que se destacam nesse sentido: primeiramente ela se distancia de uma filosofia que despreza o mundo das aparências e, em segundo lugar - e este é o ponto que nos interessa -, ela distingue o pensar do conhecer e afirma que o pensar stricto sensu não diz respeito nem à ciência, nem à tecnologia.

\section{O que é pensar}

0 pensamento é algo como uma resposta às nossas experiências no mundo. Lembramos do acontecido e procuramos compreendê-lo, de modo que o ocorrido ganhe um sentido para nós. Assim, o pensar parte da experiência concreta, mas precisa distanciar-se dela para submetê-la à reflexão, ou, nas palavras de Arendt, precisamos "parar para pensar". Isto significa que, por um momento, suspendemos as atividades em andamento e nos retiramos para um lugar no qual temos a calma e a distância suficientes para procurar compreender aquilo que não está mais diante dos nossos olhos, mas que podemos trazer para o nosso espírito. Assim nos retiramos da presença de coisas e pessoas e nos ocupamos com o que está ausente. Esse afastamento provisório do mundo possibilita que entremos numa relação conosco mesmos e procuremos responder às nossas indagações. Explica Arendt que o eu pensante entra num diálogo silencioso consigo. Essa comunicação 
é interrompida quando voltamos a falar com outra pessoa ou a executar alguma atividade.

Esse "parar para pensar" não é de modo nenhum privilégio dos filósofos ou dos intelectuais, mas uma experiência cotidiana. A cada acontecimento somos impelidos a refletir novamente, já que as perguntas que dizem respeito ao sentido não permitem respostas definitivas e sempre válidas. Assim, o eu pensante assume o lugar de quem olha para

[...] as múltiplas e incessantes ocupações da existência humana no mundo, nunca encontra uma solução definitiva para os seus enigmas, mas está pronto para respostas sempre novas à pergunta a respeito do que está realmente em questão. (Arendt, 1977, p. 211-212, tradução nossa) ${ }^{1}$

Esse esforço de compreensão não tem fim: "0 pensamento é como a teia de Penélope, desfaz-se toda manhã o que se terminou de fazer na noite anterior" (Arendt, 1995, p. 69).

0 processo pensante não persegue nenhum fim extrínseco, mas é impulsionado pela necessidade que sentimos de compreender o mundo e refletir sobre o nosso lugar nele.

Essa concepção de pensamento evidentemente difere do uso corrente do termo que, muitas vezes, entende essa atividade mental como raciocínio lógico ou como um meio para adquirir ou produzir conhecimentos, para solucionar problemas e deliberar sobre os nossos atos. Arendt (1995) não nega que possa haver também um pensar instrumental, mas o que ela enfatiza é que temos uma capacidade pensante que vai além disso.

Somos o que os homens sempre foram - seres pensantes. Com isso quero dizer apenas que os homens têm uma inclinação, talvez uma necessidade de pensar para além dos limites do conhecimento, de fazer dessa habilidade algo mais do que um instrumento para conhecer e agir. (p. 11, grifo nosso)

0 problema é que esse pensar que não tem nenhuma função prática nem constrói conhecimen- tos vem perdendo espaço para o conhecer, que se mostra capaz de satisfazer essas demandas. Por isso, Arendt ressalta que, embora haja interfaces entre o conhecer e o pensar, é essencial distinguirmos uma atividade da outra. 0 perigo - cada vez mais presente na modernidade - é perdermos de vista a relevância própria do pensar, pois, muitas vezes, aplicamos os critérios do conhecer indistintamente também à atividade do pensamento. Reflexão e busca de sentido, porém, não podem cumprir as exigências do conhecimento, seja este da esfera do senso comum, seja do âmbito das ciências. Se, no entanto, não quisermos banir uma dimensão fundamental de nossa existência, precisamos atentar para o pensar em sua especificidade, isto é, enquanto atividade do espírito distinta do conhecer e regida por critérios e objetivos próprios.

\section{A distinção}

Ao introduzir $O$ pensar, a primeira parte de A vida do espirito, Arendt (1995) anuncia: "A distinção que Kant faz entre Vernunft e Verstand, 'razão' e 'intelecto', é crucial para nossa empreitada” (p. 13).

Segundo Kant, temos a necessidade de pensar determinados assuntos, mesmo que não possamos saber nada sobre eles. Esses assuntos, conforme o filósofo, são as questões últimas que dizem respeito a Deus, à liberdade e à imortalidade. Sobre essas não podemos ter conhecimentos seguros, mas nos sentimos impelidos a pensá-las.

Arendt apropria-se dessa distinção entre a razão que pensa e o intelecto que conhece. A autora, no entanto, discorda de Kant quando ele afirma que o pensar se ocupa unicamente daquilo que está além dos limites do conhecimento. Para ela, a razão pode tratar das questões últimas, mas não se restringe a essas. 0 pensar diz respeito à reflexão sobre o sentido das coisas e das experiências, quaisquer que sejam. A atividade do pensar, portanto, não

1. No texto original lemos: "[... ] the manifold, never-ending affairs of human existence in the world, never arriving at a final solution to their riddles but ready with ever-new answers to the question of what it may be all about", cf. também o texto em português, que difere um pouco da nossa tradução (Arendt, 1995, p. 158). 
necessariamente é caracterizada pelo assunto do qual se ocupa. Refletimos sobre acontecimentos cotidianos, assim como sobre as "grandes" questões filosóficas. Desse modo, Arendt (1995) explica que Kant, apesar de sua grande descoberta, "permaneceu inconsciente com relação ao fato de que a necessidade humana de refletir acompanha quase tudo que acontece ao homem, tanto as coisas que conhece como as que nunca poderá conhecer" (p. 13).

Se o pensar não é defınido a partir de seu objeto, ele o é por aquilo que procura: o sentido - em contraposição à cognição, que busca o conhecimento.

[...] a distinção entre as duas faculdades, razão e intelecto, coincide com a distinção entre as duas atividades espirituais completamente diferentes: pensar e conhecer; e dois interesses inteiramente distintos: o significado, no primeiro caso, e a cognição, no segundo. (p. 13)

0 conhecer busca resultados seguros e verificáveis tanto no quadro da ciência como no âmbito do senso comum. Isto é, mesmo na vida cotidiana precisamos ter certeza a respeito das informações e conhecimentos dos quais dependem as atividades que exercemos. 0 pensar, em oposição a isso, não produz nenhum resultado sólido, mas diz respeito ao sentido que sempre procuramos novamente naquilo que nos ocorre. Não é possível, nem razoável, comprovar a veracidade do sentido.

0 conhecimento, por sua vez, deve ser verdadeiro, ou seja, sua validade depende da possibilidade de verificá-lo: ou ele é evidente por si mesmo, ou pode ser comprovado. De qualquer forma, não podemos discordar nem duvidar de sua validade, a não ser que possamos demonstrar ou evidenciar seu contrário. Já o pensamento não produz resultados definitivos que, uma vez consolidados, possuam uma validade por si, independentemente da atividade do pensar. Seus "resultados" só continuarão válidos na medida em que forem repensados. Se o critério da veracidade é, portanto, essencial para o conhecer, o pensar a ele não se submete. Para Arendt (1995), o ponto crucial é ("to put it in a nutshell"): "a necessidade da razão não é inspirada pela busca da verdade, mas pela busca do significado. E verdade e significado não são a mesma coisa" (p. 14).

A autora ressalta a importância do pensar não apesar da sua falta de resultados, mas justamente devido à ausência de resultados definitivos, os quais poriam em perigo a própria atividade do pensar. Com isso, ela não descarta a importância das obras de grandes pensadores, mas sublinha que estas só se tornam significativas quando perguntamos sobre o seu sentido, de modo que as repensamos.

Porém, na ótica do conhecimento, os produtos do pensamento se mostram, muitas vezes, como uma ilusão inútil, já que são transitórios e inseguros.

\section{Utilidade e sentido}

É importante destacar que Arendt, embora de certo modo faça uma defesa do pensar, de forma nenhuma descarta a relevância do conhecer. Não se trata de estabelecer uma hierarquia, mas de constatar que são duas atividades mentais distintas.

Esse tipo de procedimento, que estabelece distinções para assim melhor entender as especificidades das múltiplas faces da nossa existência, é característico para o pensamento da autora. No seu estudo sobre a vita activa, publicado sob o título A condição humana, ela distingue três atividades: $o$ trabalho, por meio do qual satisfazemos as nossas necessidades, a fabricação, que produz objetos duráveis e de uso, e $a$ ação, por meio da qual estabelecemos relações e constituímos um mundo intersubjetivo².

2. Modificamos a tradução desses três termos. A tradução em português usa os substantivos: labor, trabalho e ação (cf. Arendt, 1983). Correia sugere outra tradução, substituindo labor e trabalho, respectivamente, por trabalho $e$ obra (cf. nota sobre a tradução em Arendt, 2005, p. 196). No original em inglês encontramos os termos: labor, work e action (cf. idem). Em alemão, Arendt usa os verbos substantivados: Arbeiten, Herstellen e Handeln (cf. Arendt, 1960). Traduzimos Herstellen por fabricação, porque este termo reproduz de modo mais fiel a ideia de atividade e não de seu produto. 
Entre essas atividades da vita activa, interessa-nos neste momento a fabricação e o homem enquanto fabricante de objetos - o homo faber. Sustentamos que há um parentesco entre o conhecer e a atividade da fabricação. Arendt (1960) explica que o fabricar é de fundamental importância, pois é por meio dessa atividade que edificamos o mundo, onde "a vida humana está em casa, a vida humana que por natureza e na natureza não tem lar" (p. 14, tradução nossa) ${ }^{3}$.

A produção de conhecimento, por sua vez, também é uma atividade construtiva, a qual, de certa forma, integra a construção do mundo pelo homo faber, já que, de modo semelhante aos produtos da fabricação, os conhecimentos representam uma base relativamente sólida sobre a qual podemos nos movimentar. Assim, as atividades do fabricar e do conhecer, aparentemente tão diversas, têm algo em comum: ambas são constitutivas para o mundo, naquilo que ele tem de seguro e confiável. "A atividade de conhecer [...] é tanto uma atividade de construção do mundo quanto a edificação de casas" (Arendt, 1995, p. 45).

Esse mundo objetivo, constituído pela obra de nossas mãos e pelos conhecimentos produzidos pelo intelecto, ultrapassa a vida efêmera de cada ser humano e é o único lugar que pode representar um "lar" duradouro para as sucessivas gerações.

No que diz respeito à educação, isso significa que apresentar o mundo às crianças é também ensinar seus saberes e suas ciências (embora não no sentido especializado). Desse modo, os alunos podem compartilhar os conhecimentos do mundo, aos quais acrescentarão outros ou que poderão substituir, mas que lhes serão confiados.

Entre os diversos tipos de conhecimentos, a escola moderna tem visado cada vez mais os conhecimentos técnicos, em detrimento dos conhecimentos gerais. Os critérios tornam-se sempre mais pragmáticos, desqualificando assim o conhecimento que não é imediatamente aplicável. A transmissão de conhecimento do mundo aparentemente só se justifica se ele puder exercer alguma função prática. Assim, por exemplo, uma pedagogia que tem por objetivo o desenvolvimento de competências entende que os conhecimentos só devem fazer parte da educação na medida em que possam ser úteis na resolução de tarefas do cotidiano. Phillipe Perrenoud (2000) explica que o desenvolvimento de competências não ocorre em detrimento dos saberes, mas que é necessário "relacionar constantemente os saberes e sua operacionalização" pois, "de que lhes servirão [aos alunos] os (...) conhecimentos acumulados durante sua escolaridade, se não aprenderam a utilizá-los para resolver problemas?" (p. 15 a 19, grifo nosso).

Essa mentalidade utilitarista, presente em muitos discursos pedagógicos, nos remete à caracterização arendtiana da produção do conhecimento. Esta atividade, de fato, é de orientação utilitarista - o que é adequado a seus propósitos. Quando, porém, esse tipo de utilitarismo se torna critério para o ensino como um todo não há espaço para o pensar, ou seja, para uma reflexão que não tem nenhuma utilidade e que nem sequer produz resultados objetivos. Na perspectiva da construção do conhecimento, o pensar - improdutivo e inútil - simplesmente não faz sentido.

A atividade cognitiva, em contraposição a isso, justifica-se por seu resultado. 0 conhecimento obtido, por sua vez, é a base para se produzir novos saberes (ou, às vezes, substituir os antigos). Assim, seu fim se tornará um meio para outros objetivos. 0 conhecer, portanto, ocorre sempre "em função de", e seus resultados, embora mais estáveis do que os produtos do pensar, servirão de base e/ou de ferramenta para obter sucessivos conhecimentos.

Há aqui novamente uma nítida semelhança entre a atividade do cientista e a do homo faber, o homem fabricante, já que os produtos deste último também se transformam em meios para novas finalidades.

A cadeira, que é o fim do processo de carpintaria, só pode demonstrar sua serventia se voltar a ser um meio - seja meio de troca,

3. Neste ponto, a versão alemã - "In dieser Dingwelt ist das menschliche Leben zuhause, das von Natur in der Natur heimatlos ist" - difere da em português (Arendt, 1983, p. 15). 
seja como objeto cuja durabilidade permite que se o use como meio de tornar a vida mais confortável (Arendt, 1983).

Tanto a ciência como o trabalho do homo faber estão presos a uma cadeia interminável de meios e fins. Nela não há fins em si, mas só instrumentos, os quais, entretanto, não possuem significado por si mesmos.

Esta perplexidade, intrínseca a todo utilitarismo sistemático, que é a filosofia par excellence do homo faber, pode ser diagnosticada teoricamente como a incapacidade inata de perceber a diferença entre utilidade e significância, expressa na linguagem pela diferença entre "para que" e "em nome de quê". (p. 167)

Arendt (1983) relata que Lessing perguntou ironicamente: "E para que serve a serventia?". Nessa mesma direção, a autora sustenta que o ideal da utilidade não pode ter um sentido em si mesmo. Quando o "para que" se torna o conteúdo do "em nome de que", há uma perda de sentido: "a utilidade, quando promovida a significância, gera a ausência de significado” (p. 167).

A incapacidade de diferenciar entre utilidade e significado também é característica de pedagogias de orientação pragmática. Apesar de se enfatizar que a aprendizagem tem de ser "significativa" para a criança, com isso, muitas vezes, se quer dizer que o aprendido deve ser útil na vida cotidiana do aluno, julgando supérfluo tudo que não possui uma aplicabilidade imediata.

Em oposição a isso, Arendt (apud YoungBruehl, 1986) mencionou uma vez que, no ensino, se deve "ler os grandes livros por amor" (p. 611, tradução nossa) e não porque se procura neles soluções para quaisquer problemas.

Isso não quer dizer que não precisamos transmitir conhecimentos que sejam úteis na vida cotidiana e no mundo do trabalho, ou que não devamos desenvolver competências e habilidades que nos capacitem a resolver problemas, mas significa que não podemos submeter tudo a um mesmo critério. 0 conhecer é apenas uma forma de se relacionar com o mundo, a qual, embora necessária, por si só se mostra insuficiente, porque carece de sentido.

\section{Verdade e sentido}

Se o pensamento é movido pela busca de sentido, a cognição é impulsionada pela procura da verdade.

Para evitar mal-entendidos, é necessário avisar que, nesse contexto, Arendt (1990) se baseia numa noção de verdade posta pela ciência moderna. A época moderna, explica a autora, "acredita não ser a verdade dada ou revelada, mas produzida pela mente humana” (p. 287). É a ciência que se estabelece como o campo ao qual compete decidir o que é verdadeiro ou falso.

Nesse sentido, entende-se por verdadeiro aquilo que não pode ser refutado seja porque corresponde a fatos e dados reais, seja porque necessariamente é assim. A constatação "está chovendo" é verdadeira se de fato posso ver, sentir ou ouvir a chuva. A afirmação " $2+2=4$ " é verdadeira por não haver outra possibilidade a não ser essa. Arendt (1995) aponta que Leibniz distingue entre a verdade factual e a racional. Chegamos à primeira por meio de nossos sentidos e à segunda pelo raciocínio. Em ambos os casos, a verdade é "aquilo que somos compelidos a admitir pela natureza dos nossos sentidos ou do nosso cérebro" (p. 48).

A verdade, portanto, está "além de acordo, disputa, opinião ou consentimento" (p. 297). Há nela um elemento de coerção: "O que a ciência e a busca de conhecimento procuram é a verdade irrefutável, ou seja, proposições que os seres humanos não estão livres para refutar - são coercitivas" (p. 46).

Não nos interessa, neste ponto, discutir em que medida é possível haver verdades irrefutáveis e se esta visão corresponde à realidade da produção de conhecimento. 0 que nos parece relevante é ressaltar que as afırmações do campo do conhecimento detêm de fato um status diferente das afirmações da esfera do

4. Há neste trecho um erro grosso de tradução. No texto consta a "capacidade inata", onde deveria estar a "incapacidade inata". Este erro foi corrigido na citação. 
pensamento. Não podemos negar o Holocausto, nem que a Terra gira em torno do sol, nem que “ $2+2=4$ ”, mas a proposição "Se a justiça perece, a vida humana na terra perde o seu significado" não possui a mesma força coercitiva, porque não pode ser provada da mesma forma. Nem por isso, contudo, ela deixa de ter uma validade. 0 problema surge quando a única validade admissível passa a ser a do conhecimento verificável.

A verdade, porém - e nesse ponto Arendt se refere, sobretudo, à verdade factual -, tem uma função importante não só no que diz respeito ao conhecimento, mas também em relação às esferas de liberdade humana. Ação e pensamento, embora livres, encontram um limite em fatos cuja verdade independe deles. Aquilo, por exemplo, que já aconteceu não pode ser removido do nosso passado. Assim, a verdade delimita nossa ação, que é livre, mas que necessariamente se movimenta dentro de limites, já que há condições que não inventamos, mas que são postas.

Conceitualmente, podemos chamar de verdade aquilo que não podemos modificar; metaforicamente, ela é o solo sobre o qual nos colocamos de pé e o céu que se estende acima de nós (Arendt, 1990).

A relação entre verdade e liberdade é, portanto, complexa. A verdade propicia certa estabilidade porque confina o âmbito da liberdade, mas, ao mesmo tempo, não podemos deixar que ela dite suas regras à ação ou ao pensamento.

A importância que Arendt atribui a essa temática remete novamente às suas reflexões sobre o totalitarismo. Em sua análise dos regimes totalitários, ela procurou compreender de que modo foi possivel extinguir a liberdade. E aponta, entre outros, para dois elementos que são relevantes para a nossa discussão. Por um lado, a mentira organizada retirou o chão que a verdade factual e a experiência deveriam ter oferecido, e que podia ter imposto limites à atuação. Por outro lado, usou-se a força coercitiva de afırmações pseudocientíficas para dominar o pensamento e a ação, isto é, para impedir qualquer opinião ou decisão livre.

Para a ideologia nazista, toda "ação" política devia partir da premissa "verdadeira" e "inquestionável" da superioridade de uma raça. Essa suposta "verdade" não era apenas constatada, mas transformada em projeto político. Os passos que esse programa seguia eram ditados pela premissa da "raça superior", ou seja, não eram tidos como escolhas, mas como ações necessárias que derivavam diretamente de uma verdade. Segundo essa ideologia, a ação era, portanto, determinada por um processo de dedução lógica que não dependia de decisões humanas e que não admitia contradições. Assim, a lógica, que não mantinha mais nenhuma relação com a experiência real das pessoas, ditava o que era certo e errado. Nesse sentido, Hitler orgulhava-se "do seu supremo dom de "raciocínio frio como o gelo”, que levava "as implicações ideológicas aos extremos da coerência lógica”.

Quem concordasse [...] com o fato de que o direito de viver tinha algo a ver com a raça e não deduzisse que era necessário matar as "raças incapazes”, evidentemente era estúpido ou covarde. Essa lógica persuasiva como guia de ação impregnava toda a estrutura dos movimentos e governos totalitários. (Arendt, 1989, p. 524)

Segundo Arendt (1989), um elemento que, entre outros fatores, levava as pessoas a se submeterem a essa lógica, contra qualquer bom senso (gesunder Menschenverstand), era o medo de entrarem em contradição consigo mesmas e, assim, perderem o "chão debaixo dos pés", num tempo em que o sentimento de insegurança era generalizado, já que se perderam as referências que a tradição oferecia e que garantiam um mínimo de segurança para se orientar no mundo. Essa situação de incerteza contribuía para que as pessoas se agarrassem a um raciocínio cuja correção era garantida pela lógica e que, portanto, podia mostrar sem falha o caminho "certo" a ser seguido. Assim, o raciocínio lógico segundo o qual quem diz "A" também precisa dizer "B" se transformou num terrível "princípio de ação".

0 preparo das vítimas e dos carrascos, que o totalitarismo requer [...] não é a ideologia em si 
[...], mas a sua lógica inerente. Nesse ponto, o argumento mais persuasivo - argumento muito do gosto de Hitler e de Stálin - é: não se pode dizer A sem dizer B e C, e assim por diante, até o fim do mortífero alfabeto. Parece esta ser a origem da força coerciva da lógica: emana do nosso pavor à contradição [...] e com essa contradição toda a tua vida perde o sentido. (p. 525)

Essa "lógica" toma conta não só da ação, mas corrompe também o pensamento. Este fica isolado daquilo que devia ser seu objeto - as experiências vividas pelas pessoas - e não tem liberdade em sua busca de sentido, já que se encontra sob o ditame da lógica. A suposta "verdade" à qual a ideologia remonta destrói o pensamento porque faz supor "que sentido e coerência lógica são a mesma coisa” (Arendt, 2003, p. 969, tradução nossa) 5 .

0 totalitarismo mostra, portanto, como, no extremo, a lógica ideológica pode levar à extinção da liberdade não só da ação, mas também do pensamento, em nome de uma suposta "verdade". Quem se submete a ela deixa de pensar, já que o pensamento por definição é insubmisso a qualquer tirania: "0 pensamento, como a mais livre e a mais pura das atividades humanas, é exatamente o oposto do processo compulsório de dedução" (Arendt, 1989, p. 526).

A experiência totalitária nos alerta que, toda vez que submetemos nossa capacidade de pensar a alguma verdade incontestável (pouco interessa se esta é verídica ou o é apenas supostamente), pomos em perigo a liberdade do pensamento. Isso é válido para as "verdades" totalitárias, mas também para outras verdades, produzidas pela ciência ou pelo conhecimento em geral. Se, por um lado, precisamos destas últimas enquanto "chão" no qual pisamos, e que é necessário para que possamos nos movimentar no mundo, por outro lado nenhuma verdade deve impedir o próprio movimento, ou melhor, a liberdade de movimento.

Voltemos agora à questão do lugar do conhecer e do pensar na educação. Parece-nos que transmitir conhecimentos verdadeiros é uma das tarefas fundamentais da escola. A matemática, a física, a história e a geografia, entre outras, devem fazer parte do currículo. Não podemos esquecer, entretanto, que a aquisição ou produção desses conhecimentos também está relacionada a escolhas que dependem do pensamento e do nosso lugar no mundo, já que o conhecer não nos diz quais saberes devem ser transmitidos, nem como interpretamos e julgamos determinados dados ou fatos, nem de que forma os ensinamos.

0 papel do pensar na educação, porém, deve ir além disso e contribuir para a capacidade de reflexão da própria criança, já que esta não só é capaz de adquirir conhecimentos, mas também de pensar, isto é, de compreender as experiências humanas no mundo e refletir sobre o seu significado.

Se submetermos as relações pedagógicas e os conteúdos curriculares à "tirania da verdade" colocaremos em perigo aspectos preciosos de um pensar que "vai além dos limites do conhecimento" e que, mesmo assim - ou melhor, que, por isso mesmo -, precisa fazer parte de uma educação que pretende introduzir as crianças no mundo humano, com o qual podemos nos relacionar de diversas formas.

Um dos aspectos que facilmente se perde e que está diretamente ligado à capacidade do pensar é o encanto ou a admiração, a qual, segundo os gregos, move o pensar ou, como poderíamos dizer também, surge com essa atividade do espírito. Ela difere da "sede de conhecimento" que busca saberes concretos. A poesia, por exemplo, pode estar cheia desse encanto. Pensemos no poeta que declara sua admiração pela beleza da natureza falando do "canto do riacho". Não lhe faríamos justiça se lhe respondêssemos que o riacho não pode cantar, já que não possui cordas vocais ou porque a água é matéria inanimada - independentemente do fato de que estaríamos falando a verdade.

Podemos conhecer dados e leis da natureza e fatos do mundo, mas o significado que atribuímos a eles, à nossa existência no mundo

5. Na versão alemã, lemos: "dass Sinn und Stimmigkeit das gleiche sind". Este trecho não consta na versão em português (0 texto em alemão é uma versão mais tardia e revisada pela própria autora para a publicação desta obra na Alemanha). 
e às nossas experiências, é de nossa autoria, e nisso reside a liberdade do pensamento. Essa é a principal diferença entre o conhecer e o pensar.

0 poeta e amigo de Arendt, Wystan $\mathrm{H}$. Auden, escreve um poema que toca nessa temática, e que a autora cita no seu texto:

Décadas atrás, subitamente você chegou em meio à infınita cascata de criaturas vomitadas das entranhas da Natureza. Um evento aleatório, diz a Ciência.

[...]

Aleatório uma ova! Um verdadeiro milagre, digo eu,

pois quem duvida que ele estava destinado a ser? (Arendt, 1995, p. 47). ${ }^{6}$

Há pensamentos que não fazem sentido do ponto de vista da ciência ou do conhecimento de modo geral. A reflexão pode sempre ser julgada pela falta de resultados válidos ou por sua inutilidade, mas essa crítica não atinge um pensar que não está interessado em verdades únicas ou verificáveis e que, justamente por isso, goza de uma liberdade que não existe sob os critérios da veracidade ou da utilidade. Assim, Arendt (1995), retomando mais uma vez o poema de Auden, explica:

A proposição de que todos que são "estavam destinados a ser" pode ser facilmente refutada; mas a certeza do eu "estava destinado a ser” sobreviverá intacta à refutação, porque é inerente a toda reflexão em que o pensamento se ocupa do eu-sou. (p. 48)

\section{Considerações finais}

Constatar que os conhecimentos são passíveis de ensino e que a escola tem um papel importante na aquisição de saberes é relativamente consensual, mesmo que haja uma ampla discussão sobre as metodologias a serem seguidas.

No que diz respeito ao pensamento, as coisas são mais complicadas. Segundo Arendt, não podemos ensinar a pensar, não há métodos ou regras que possamos transmitir. 0 que, contudo, podemos fazer é compartilhar o sentido que atribuímos às experiências e aos pensamentos, e que queremos legar aos mais novos. Os alunos podem então repensar e ressignificar o que herdam a partir do seu modo de se relacionar com esse legado e estabelecer a sua pertença singular a este mundo. Segundo Arendt (2004):

Pensar e lembrar [...] é o modo de deitar raizes, de cada um tomar o seu lugar no mundo a que todos chegamos como estranhos. 0 que em geral chamamos de uma pessoa ou uma personalidade, distinta de um mero ser humano ou de um ninguém, nasce realmente desse processo de pensamento que deita raízes. (p. 166)

Só quem finca raízes pode tomar uma posição e renovar ou conservar o lugar ao qual pertence. Desse modo, o pensar, embora voltado para o passado e mesmo que não planeje ou dê instruções, acaba por ser pressuposto de uma ação que não se isenta de sua responsabilidade pelo mundo.

A experiência, porém, mostra que, se não é factível sobreviver sem o mínimo de conhecimentos, é realmente possível negar-se a pensar: simplesmente não parar para refletir, não se perguntar sobre o significado das coisas e não enxergar que os nossos atos dizem respeito ao mundo e às pessoas nele.

A educação certamente pode dar a sua contribuição para evitar que isso aconteça. Não há, no entanto, nenhuma garantia. Podemos contar as histórias do mundo que carregam significados, instigar os alunos a se perguntarem de que modo estas lhes dizem respeito e se atos e palavras possuem algum significado que vá além da sua funcionalidade. Nesse sentido, uma educação para o pensamento certamente não se resume à transmissão de sabedorias. A tarefa da educação - diante de um pensar que dispensa pré-requisitos porque não está condicionado a

6. 0 poema em inglês: "Unpredictable, decades ago, You arrived / among that unending cascade of creature spewed / from Nature's maw. A random event, says Science. / Random my bottom! A true miracle, say I, / for who is not certain that he was meant to be?" (Arendt, 1977, p. 60-61). 
conhecimentos nem ao grau de instrução ou de inteligência - talvez fosse, muito mais, provocar e cutucar, atrair e encantar os jovens pela experiência pensante. Se, contudo, pensarão ou não, e por onde enveredará a sua reflexão, foge de qualquer controle.

Arendt (1995), no final de sua abordagem sobre o pensar, refere-se, mais uma vez, à possível recusa de pensar:

0 pensamento, em seu sentido não-cognitivo e não-especializado, como uma necessidade natural da vida humana, [...] não é uma prerrogativa de poucos, mas uma faculdade sempre presente em todo mundo; do mesmo modo, a inabilidade de pensar não é uma imperfeição daqueles muitos a quem falta inteligência, mas uma possibilidade sempre presente para todos - incluindo aí os cientistas, os eruditos e outros especialistas em tarefas de espírito. Todos podemos vir a nos esquivar daquela interação conosco mesmos [...]. Uma vida sem pensamento [...] [no entanto] não é apenas sem sentido; ela não é totalmente viva. Homens que não pensam são como sonâmbulos. (p. 143)

Assim, a nossa tarefa talvez seja despertar os alunos para uma atividade do espírito que pode nem sempre ser gratificante, mas que certamente os torna mais humanos.

\section{Referências bibliográficas}

ARENDT, H. A condição humana. Tradução R. Raposo. Rio de Janeiro: Forense Universitária, 1983. . Denktagebuch 1950-1975. Organizado por Ludz, U./Nordmann, I. München: Piper, 2002. Elemente und Ursprünge totaler Herrschatt. 9. ed. München: Piper, 2003. Entre o passado e o futuro. São Paulo: Perspectiva, 1990. . Responsabilidade e julgamento. Tradução Rosaura Eichenberg. São Paulo: Companhia das Letras, 2004. The life of mind. New York: Harcourt Brace Jovanovich, 1977. Origens do totalitarismo. Tradução Roberto Raposo. São Paulo: Companhia das Letras, 1989. . Trabalho, obra, ação. Tradução Adriano Correia. Cadernos de Ética e Filosofia Política, São Paulo, n. 7, v. 2, p. 175-201, 2005. A vida do espírito. Tradução Antonio Abranches e Helena Martins. Rio de Janeiro: Relume-Dumará, 1995 Vita activa oder Vom tätigen Leben. Stuttgart: Kohlhammer Verlag, 1960. 1976.

Was bleibt? Es bleibt die Muttersprache. In: REIF, A. (Org.). Gespräche mit Hannah Arendt. München: R. Piper \& Co. Verlag,

PERRENOUD, P. Construir competências é virar as costas aos saberes? Patio - Revista Pedagógica, ano 3, n. 11, p. 15 a 19, nov. 99/jan. 2000.

YOUNG-BRUEHL, E. Leben, Werk und Zeit. Frankfurt, 1986.

Recebido em 21.12.09

Aprovado em 22.06.10

Vanessa Sievers de Almeida é bacharel em Teologia (Faculdade de Teologia da Igreja Metodista), com licenciatura plena em Pedagogia (FEUSP) e doutorado, pela FEUSP, na linha de pesquisa "Filosofia e Educação". 